\title{
Educação Física na Europa e no Brasil: um sentido comum que mostra uma identidade universal António Camilo Cunha
}

\section{Resumo}

Apoiando-se nas várias concepções/tendências de Educação Física em duas regiões geográficas diferentes - Europa e Brasil - o autor tenta mostrar que existem concepções idênticas e diferentes de olhar o ato pedagógico da Educação Física em contextos formais, informais e não formais. Quanto ao sentido do idêntico, far-se-á um elogio à ideia de "um comum" que estrutura uma identidade global e, por isso, universal. Esse fato parece evidenciar que existe um caminho (eixo) ontológico/ metafísico comum que trespassa e diz o que é a Educação Física. Essa constatação está acima das diversidades (e convicções) sociais, curriculares, linguísticas, políticas, ideológicas e geográficas.

Palavras-chave: Educação Física; abordagem ontológica; abordagem epistemológica; Europa; Brasil; análise comparativa. 


\section{Abstract \\ Physical Education in Europe and Brazil: a common sense that shows a universal identity}

Relying on various concepts / tendencies of Physical Education in two different geographic regions - Europe and Brazil - the author tries to show that there are similar and different conceptions of looking at the act of teaching Physical Education in formal, informal and non-formal contexts. Through the sense of identical it will be done a compliment to the idea of "a common", that organizes a global identity and therefore universal. This fact seems to evidence that there is a common ontological/ metaphysical way (axis) that pierces and tells what Physical Education is. This conception is above social, curricular, linguistic, political, ideological and geographical diversities (and convictions).

Keywords: Physical Education; ontological approach; epistemological approach; Europe; Brazil; comparative analysis.

\section{Introdução}

Este ensaio teórico tem como objetivo realizar uma síntese das grandes concepções/tendências da Educação Física na Europa e no Brasil, que se desenvolvem em espaços e tempos formais, informais e não formais. Depois da análise de cada uma das realidades e concepções, pode-se eventualmente fazer elevar um sentido comum que estrutura uma identidade global e, por isso, universal. Esse fato parece evidenciar que existe um sentido ontológico/metafísico comum que está acima das diversidades (e convicções) sociais, curriculares, linguísticas (linguagem), políticas, ideológicas e geográficas.

Trata-se de uma reflexão teórica (comparativa) que partiu da análise de duas realidades: a da Educação Física da Europa e a do Brasil, tomando como fonte de dados alguns escritos (textos) e reflexões do autor sobre a problemática.

Iremos constatar ao longo do texto que vai emergir um sentido comum - um sentido ontológico/metafísico - que se dá a conhecer em três eixos estruturantes/ universais:

1) o homem-todo;

2) as propriedades - as palavras intrínsecas, íntimas e estruturantes da Educação Física: brincar, jogar, competir, "novos"/"antigos" (ideia de história) movimentos e "novas" formas de pensamento e ação;

3) a cultura e a axiologia.

Dessas constatações, tomamos a liberdade de dizer que a Educação Física tem uma essência primeira (ontológica/metafísica) que é do campo do universal, tem uma identidade universal a ponto de podermos afirmar que, quando um homem se move, é toda a humanidade que se move. 


\section{Educação Física na Europa}

Ao fazermos uma análise (macro) à Educação Física na Europa (Cunha, [no prelo]), podemos dizer que existem (pelo olhar da história) pelo menos seis grandes concepções, que apresentamos em seguida e de forma sintética:

1) Psicomotricidade - concepção muito ligada à corrente francesa. Neste envolvimento, para além da dimensão aprendizagem e desenvolvimento psicomotor, existe também a ideia do lúdico, do jogo, dos movimentos fundamentais, da psicologia do comportamento e desenvolvimento (a estruturação de fases, etapas de aprendizagem). As técnicas desportivas (dimensão desportiva) também estão presentes - aliás, essa perspectiva é transversal a todas as tendências que iremos apresentar. Esta tendência é identificada com maior enfoque em países como França, Portugal, Espanha, Bélgica, Itália, Grécia.

2) Desportivista - concepção muito ligada ao modelo alemão. Os profissionais apresentam uma dupla formação (por exemplo, professores de Educação Física e de Biologia). A Educação Física aparece como disciplina "menor", dando maior ênfase ao desporto (que, no entanto, em nosso entendimento, é uma dimensão da ação física). Esse fato tem a ver com o traço cultural forte muito ligado à ideia de atitude, disciplina, eficácia, sucesso, trabalho, produtividade, rendimento (dimensão quantitativa). No entanto, deve-se salientar algumas propostas que fazem o elogio à Educação Física de cariz pedagógica nomeadamente por meio da corrente "escola do movimento - movimentar-se". Nesse contexto, o movimento aparece como algo intrínseco ao homem - homem interior, mas também experiencial, intencional -, emergindo daqui a ideia do fenomenológico, interpretativo, hermenêutico.

3) Educação Desportiva - esta concepção faz o elogio ao desporto como uma forma de entender a vida e a cultura. Quando nasce uma criança, ela é sócia de um clube, de uma cultura. Muito associada a esta perspectiva está também a defesa do conceito do Estado/Nação e da tradição preservação e divulgação da tradição (cultura), por exemplo, dão grande atenção à defesa e divulgação dos jogos tradicionais. Mais do que passado (raiz, arquétipo), esses jogos são coisa do futuro - mostram, iluminam o futuro. Esta tendência é típica de países como Inglaterra, Escócia, Irlanda.

4) Especialização Precoce - concepção que faz elevar o desporto precoce, especialização precoce, detecção de talentos, rendimento. Aqui ainda está expressa a ideia de que o cidadão é pertença do Estado, portanto, é uma concepção ainda influenciada pelos caminhos político-ideológicos. Os antigos países do leste europeu ainda preconizam esta tendência.

5) Voluntariado - A Educação Física é vista como uma concepção de vida muito ligada ao tempo livre, à socialização, aos valores (o axiológico), à ecologia, à saúde e ao lazer. É também um traço cultural que parece convocar a antiga metáfora socrática: "tempo livre para se dedicar ao eu 
interior". Concepção de grande representação social e familiar e se situa em países como Suécia, Noruega, Holanda, Dinamarca.

6) "Novos" Movimentos - A Educação Física que convoca os "novos" movimentos - na terra, no ar, na água -, resultado da evolução técnica e de um retorno do homem à natureza. A este fato, não estão alheios os novos discursos político-sociais sobre a proteção e promoção da natureza/ ecológico.

\section{Educação Física no Brasil}

Ao fazermos igualmente uma análise (macro) à Educação Física no Brasil (Azevedo, Shigunov, 2001), podemos dizer que existem (pelo olhar da história) pelo menos 11 grandes concepções que apresentamos em seguida e de forma sintética.

\section{A) Concepções preditivas}

A.1) Concepção Aulas Abertas - defende a vida de movimento das crianças, materializado nas histórias de vida e na biografia motora (desportiva) dos estudantes de Educação Física como processo formativo (é uma concepção formativa também). Esta concepção considera a possibilidade de co-decisão no planejamento das atividades desportivas/motoras (objetivos, conteúdos, competências, formas pedagógicas e didáticas) entre professores e alunos. Esse olhar defende também uma nova visão formativa e profissional pela compreensão de professores e alunos sobre o sentido que tem a aula - jogo, movimento, desporto, entre outros (Hildebrandt, Laging, 1986).

A.2) Concepção Atividade Física para a Promoção da Saúde - defende uma nova atitude pedagógica que tenha em consideração metas (organização e desenvolvimento de experiências) em termos de promoção da saúde e formas de tornar as crianças e os jovens mais ativos fisicamente tanto no presente quanto no futuro (vida adulta). Esta concepção faz elevar a ideia de qualidade de vida tendo como pano de fundo a consciência da saúde, do lazer, dos hábitos alimentares e dos estilos de vida não sedentários (Guedes, Guedes, 1993; Nahas, 1998).

A.3) Concepção Construtivista-Interacionista - sua intenção é a construção do conhecimento a partir da interação do sujeito com o mundo, respeitando o universo cultural do aluno. Explora, assim, as diversas possibilidades pedagógicas de atividades motoras espontâneas, propondo gradualmente tarefas cada vez mais complexas e desafiadoras com vista à construção do conhecimento - mediante métodos não diretivos -, como acontece no modelo tradicional da prática da Educação Física. O "jogo" é o elemento de base para a dinâmica pedagógica (modo/meio de ensinar), pois convoca um ambiente lúdico de prazer. Corpo e mente que se emancipam (Freire, 1992). 
A.4) Concepção Crítico-Emancipadora e Didática Comunicativa - enfatiza a possibilidade de ensinar o desporto pela transformação didáticopedagógica, tornando o ensino escolar como um momento em que crianças e jovens fazem elevar a competência crítica e emancipada; uma educação mais emancipadora que afaste as imagens negativas da tradição autoritária e domesticada (instrumentalização técnica) da Educação Física. A emancipação neste envolvimento é entendida como um processo contínuo de libertação do aluno das condições "limitadoras" das suas capacidades racionais críticas e até mesmo do seu agir no contexto sociocultural desportivo. O conceito crítico é, nesse caso, entendido como a capacidade de questionar e analisar as condições e a complexidade de diferentes realidades de forma fundamentada - pelo agir comunicativo, questionador, argumentativo, autoavaliativo (Kunz, 1996).

A.5) Concepção Crítico-Superadora - tem como fundamento o discurso político-pedagógico, convocando questões como a justiça social, o poder, interesse e contestação crítica à luz da dimensão social (realidade dos homens). A Educação Física, nesse contexto, é vista como uma disciplina que trata o jogo, a ginástica, o desporto, a capoeira e a dança como conhecimentos da cultura corporal do movimento. É mais do que transferir e repetir conhecimentos, essa disciplina cria a possibilidade de sentido crítico (constatar, interpretar, compreender) desses conhecimentos à luz da história e do bem social (sua conquista); tem um sentido político de participação e transformação forte (Soares et al., 1992).

A.6) Concepção Desenvolvimentista - tem como meio e fim principal da Educação Física o movimento. Toma como referência os ensinamentos do crescimento físico, fisiológico, motor, cognitivo, afetivo e social. Tem como olhar pedagógico-didático a aprendizagem do movimento, a aprendizagem por meio do movimento e a aprendizagem sobre o movimento (Tani, 1998). Esta concepção defende o maior estímulo (diversidade e complexidade de movimentos) para que as habilidades motoras sejam alcançadas.

A.7) Concepção da Educação Física Plural - encara o movimento humano enquanto técnica corporal construída culturalmente e definida pelas caraterísticas de determinado grupo social. Considera todo gesto como uma técnica corporal por ser uma técnica cultural. A Educação Física escolar deve ter como tarefa ofertar vários sentidos (pluralidade de ações) motores, abrangendo todos os alunos, seja qual for a sua condição - alto, baixo, magro, obeso, menos hábil, menina (Daolio, 1996). A dimensão eficácia, rendimento, "certo" ou "errado" não é tida em consideração.

\section{B) Concepções não preditivas}

B.1) Concepção Humanista - situa-se no plano da formação integral. As atividades propostas (jogo, dança, desporto, ginástica, etc.) constituem- 
se como meios de formação integral, e não como fim. O professor é um orientador de aprendizagem, cabendo a ele a promoção do crescimento pessoal e social (crítica, participação, cidadania) dos alunos. As atividades são selecionadas pelo professor e pelos alunos a partir dos seus interesses e necessidades (Oliveira, 1985).

B.2) Concepção Psicomotricista - utiliza a atividade lúdica e o jogo como impulsionadores dos processos de desenvolvimento e aprendizagem. Explora as condutas motoras: lateralidade, coordenação, equilíbrio, percepção, história motora, bem como o jogo e seus significados. Aproxima a história da psicomotricidade associada às condutas exploratórias e espontâneas das crianças. A ideia de assimilação e a de acomodação estão presentes, assim como a de sujeito interno e externo (Le Boulch, 1986).

B.3) Concepção Sistêmica - nela, a Educação Física é concebida "como um sistema adaptativo, complexo, hierárquico e aberto" (Betti, 1991, p. 134). O autor destaca que o caráter aberto do sistema se manifesta na influência recebida do nível macrossocial por meio da política educacional e de outras forças sociais que possuem interesse pela Educação Física, com mais evidência o sistema militar e o esportivo. A Educação Física deve proporcionar uma vivência corporal na dimensão experiência da cultura do movimento. Defende a não exclusão e a estimulação de diversidade de atividades pela partilha e transformação das formas culturais da atividade física - jogo, desporto, dança, ginástica. Enfatiza a importância de conduzir o aluno na descoberta dos motivos da prática de sua atividade física como forma de cultura e cidadania (Betti, 1994).

\section{A Educação Física: um sentido comum que mostra uma identidade universal}

Perante as diversas concepções apresentadas, somos impelidos a perguntar: Afinal, o que é a Educação Física?

Pergunta tão simples e ao mesmo tempo tão complexa. Simples na sua essência, complexa na sua interpretação (nossas interpretações - 10 concepções no Brasil e 6 na Europa - e aquilo que há de vir). Peguemos na simples - peguemos na essência.

A Educação Física é antes e mais do campo ontológico/metafísico, essa é sua essência.

Para desconstruirmos essa constatação ontológica/metafísica, colocamos duas questões, também ontológicas/metafísicas:

A Educação Física existe? Sim, existe. Todos nós, como profissionais e "espíritos de missão", mostramos e desenvolvemos as propriedades dela.

Como sabemos que ela existe? Ela existe porque há um ser material (corpo) e espiritual - o homem - que vai mostrar as propriedades da Educação Física (por 
exemplo, de movimento), e, por outro lado, elas vão ajudar o mesmo homem a ser mais... a ir para diante.

Assim, de forma simples, podemos dizer que a Educação Física é um conjunto de propriedades (no sentido de propriedade/qualidade) que fazem parte do universo e do homem - este último, pelo pensamento e pelo movimento (corpo), dá sentido e significado a essas propriedades.

A Educação Física constitui-se assim como palavra - ela é essência, propriedade(s), manifestação e possibilidade.

Nesse enfoque, a Educação Física - antes de ser sociológica, antropológica, política, ideológica, biológica, física, química, mecânica, científica/epistemológica, matemática, número - faz parte (é) do campo ontológico/metafísico que quer fazer história individual e coletiva. É aqui que, em nosso entender, a Educação Física se legitima e encontra a sua identidade.

Ela é universal e, por isso, seu chão se encontra na filosofia (que se preocupa com os universais), e não em quaisquer das concepções de Educação Física - campos parcelares. Com isso, não queremos fazer crítica às várias concepções de Educação Física, pelo contrário, todas elas contribuem de uma forma ou de outra para dar visibilidade e mostrar sua essência.

\section{Há uma ideia generalizada de que a Educação Física está em crise (crise de identidade)}

Crise pela existência de inúmeras concepções de Educação Física, que chamam a si métodos e objetos de intervenção pedagógica, e de pesquisa muito particulares - levando a uma dispersão e a lutas de legitimação que parecem procurar exclusividades.

Crise porque o modelo desportivo e a pesquisa predominantemente positivista, quer na formação quer na profissão (escola), parece continuar a ser dominante, e que pode tudo ou quase tudo.

Crise porque os modelos pedagógico-didáticos continuam presos a um a priori, materializados em currículos, modelos, programas rígidos. A tão falada didática da relação, da configuração, da interação e do contexto parece não existir - e se existe talvez não numa forma desejável.

Crise pela discrepância entre o mundo pensado e o mundo vivido. De um lado estão alguns estudiosos com argumentos teóricos numa crítica - crítica forte (palavra/ teóricos) perante a Educação Física -, do outro lado, os práticos preocupados com a visibilidade numérica da sua ação e pesquisa, por exemplo, o excesso de números - pesquisa/artigos de cariz positivista.

Crise pela falta de consenso sobre os caminhos epistemológicos a seguir. De um lado, os positivistas lógicos (com seu excessivo rigor metodológico e com grande apetite pela generalização), do outro, o sentido mais qualitativo, fenomenológico, hermenêutico, linguagem que, perante uma realidade complexa, dinâmica, multidimensional, parece defender o ousar metodologicamente. Qual o valor de cada um desses caminhos? 
Poderíamos chamar outras realidades que mostram a (eventual) crise, mas a questão que gostaríamos de colocar é: Elas são as maiores responsáveis pela crise?

Em nosso entendimento, não. Não cremos que a crise seja de responsabilidade exclusiva dessas realidades. A existir uma crise, ela está assente numa crise primeira, numa de origem: a crise é ontológica - crise da interioridade. A crise será o resultado de uma ausência de consciência consciente sobre os três eixos que estruturam o sentido ontológico e metafísico da Educação Física. São esses eixos que mostram as propriedades, as qualidades - as palavras - da Educação Física: Que eixos são esses?

\section{Os eixos que mostram as propriedades/palavras da Educação Física}

$1^{\circ}$ eixo - A ideia de homem-todo: esse homem-todo já nos tinha sido transmitido pela herança helênica. Ele é o sensível, o inteligível, o imanente e o transcendente, e só existe porque há corpo e movimento à espera que o impulsione para um fim, bom fim, fim perfectível. A Educação Física para ser ela terá, necessariamente, que convocar o homem-todo.

$2^{\circ}$ eixo - As propriedades (palavras) estruturantes da Educação Física: brincar, jogar, competir, "novos"/"antigos" (ideia de história) movimentos e "novas"/"antigas" formas de pensamento e ação são as palavras, as essências, as unidades de sentido, as existências, os princípios fundadores e intemporais. Essas são as palavras que mostram e dizem a Educação Física, a qual, para ser ela, terá necessariamente que convocar o brincar, o jogar, o competir e os "novos" movimentos/"novas" formas de pensamento e ação. Os profissionais da Educação Física conhecem muito bem essas palavras/propriedades, contudo, parece que elas se confundem na teoria e na prática - parece existir uma dificuldade em trabalhar, em diferenciar pedagogicamente, conforme os contextos, as necessidades e as pessoas envolvidas. Por outro lado, a formação desses profissionais (graduação, formação continuada e especializada) parece não fazer um esclarecimento claro e preciso desses sentidos, dessas essências. Apesar de essas essências serem trabalhadas, percebidas, pesquisadas, elas não se expressam de acordo com o seu real valor.

$3^{\circ}$ eixo - A cultura e a axiologia: a Educação Física para ser ela terá, necessariamente, que convocar a cultura e as questões axiológicas.

\section{A Educação Física e seus eixos (propriedades, palavras) - desenvolvimento}

Analisemos com mais cuidado cada um dos eixos (propriedades, palavras).

$1^{\circ}$ eixo - A ideia de homem-todo

Ele é um ser sensível, inteligível, imanente e transcendente. É do campo da metafísica realista, que na cultura ocidental tem Parmênides, Platão e Aristóteles como grandes precursores (Morente, 1980). Às perguntas da metafísica realista, vão 
surgir respostas realistas: Quem existe? O que existe? Existem as coisas, o mundo das coisas e o homem entre elas. As coisas, os seres, o homem, as substâncias têm inteligibilidade, e podemos conhecer o mundo das coisas pelo estabelecimento de conceitos e propriedades. A inteligibilidade das coisas mesmas é o postulado essencial do realismo. Mas o homem tem também outra grande força - o seu idealismo (metafísica idealista), pela capacidade de convocar a utopia, o mito, o simbólico e o metafórico.

Nesse sentido, o homem-todo é do campo realista e idealista. A Educação Física também o é, pois as propriedades são suas e do próprio homem - na realidade e na mente.

\section{$2^{\circ}$ eixo - As propriedades/palavras intrínsecas/íntimas da Educação Física}

Analisemos cada uma das propriedades/palavras.

\section{A $1^{\text {a }}$ propriedade/palavra - O brincar}

O brincar é o início. A criança brinca, o adulto brinca, os animais brincam: o cão, o gato, os pássaros, etc. O brincar contém a raiz, a potência, a luz inicial. Contém uma dimensão pré-reflexiva, estruturando-se como fundação, arquétipo, recolhimento. Estamos aqui perante a ideia de anúncio, de a priori, do amoroso, do sensível, do sonho acordado e, se quisermos, de uma certa forma de poesia. O brincar é da ordem do movimento quente. Esta é a primeira propriedade que é fenomenológica e existencialista - coisa da interioridade primeira e profunda. É a nossa ligação com o divino.

\section{A $2^{\mathrm{a}}$ propriedade/palavra - O jogar}

O jogar é o meio. O jogo só existe porque há uma palavra mágica que a razão fez nascer: regra. Ele é uma forma de organizar o que já existe (brincar). É um modo de dar ordem, sistematizar, mas também criar o novo - novos movimentos, novos pensamentos. Só o homem joga - pensando na racionalidade humana; mas a natureza também joga - pensando numa racionalidade da natureza. O jogo coloca em marcha aquilo que já aconteceu, dando-lhe ordem - com a regra e pela regra. O homem precisa de ordem.

\section{A $3^{\mathrm{a}}$ propriedade/palavra - O competir, a competição}

A competição emerge como mola de impulso. Depois de "ultrapassar" (faz parte da nossa massa) a ideia de competir para sobreviver, ter poder, território, alimento, reprodução - os animais fazem isso -, a humanidade descobriu na competição/desporto a oportunidade de ser mais - real, simbólico e metafórico. É nessa ideia de competição que encontramos palavras (relacionadas à ação) como: trabalho, superação, treino, esforço, rendimento, ir mais além. 
É uma Educação Física que mostra o desporto - pluralidade desportiva (e o desporto escolar). Uma Educação Física do rendimento, da competição, do resultado, dos "melhores" - que devem ser cada um e, por isso, os "piores" também estão ali. Um desporto com forte sentido educativo e pedagógico. Educação no, para e pelo desporto. Um modelo de educação desportiva no sentido de todos e para todos.

\section{A $4^{\mathrm{a}}$ propriedade/palavra - Os "novos"/"antigos" (ideia de história) movimentos e "novas" formas de pensamento e ação}

É a Educação Física das atividades em espaços modernos e na natureza (ar, terra, água). Traduz um certo eterno retorno do homem à natureza, ao primeiro locus de felicidade, à primeira estética, mas também a Educação Física do homem na (sua) modernidade: turismo, lazer, saúde, danças, artes, lutas, treino, mercado, mídia, trabalho, bem-estar, fitness, aventura, risco, recreação, tensão, expressão, cosmético, novas interpretações da linguagem, da comunicação, da experiência. É uma Educação Física que convoca outras formas de intervenção, assim como outras áreas do ser, do saber e do fazer humano.

Todas essas propriedades têm quadros teóricos, práticos, históricos, sociais, de pesquisa, pedagógicos, didáticos, próprios, mas também canais de fértil comunicação (fluxo) entre elas. Por outro lado, todas elas estão edificadas em dois pilares que funcionam como mola de impulso: a cultura e a axiologia.

\section{$3^{\circ}$ eixo - A cultura e a axiologia}

\section{A cultura}

Muitas áreas do conhecimento abordam a ideia de cultura. Identificamo-nos aqui com o olhar de um grande pensador português, Ferreira Patrício (2009), o qual destaca que a cultura é aquilo que o homem acrescenta à natureza (sua natureza - ontológica; natureza/natureza - ecológica) em virtude da sua atividade criadora e transformadora.

A cultura eleva-nos acima da nossa condição animal e torna-nos mais completos e inovadores, mais largos, profundos, mais leves, ricos e desejavelmente melhores - não necessariamente melhores. A cultura é um caminho de excelência para atingir a liberdade.

Um homem culto tem apontado a si duas setas: uma para a razão e outra para o coração, que fará dele um sábio. No entanto, também gostaríamos de ressaltar que existe cultura que pode não ser boa, como a que não promove ideais de humanização - estética/ética.

A Educação Física encontra na cultura (e vice-versa) um campo fértil para ser mais... tender para a sabedoria.

\section{A axiologia}

Existem várias taxonomias sobre os valores - da religião, da fé, da racionalidade, da cultura, do ontológico (este talvez o grande valor). 
Identificamo-nos neste contexto com a análise feita por Ricoeur (1990; 2000) sobre a ideia de moral e ética.

A moral corresponde ao anterior. É a moral pensada, a institucionalização de códigos, as normas jurídicas - são os mínimos, o deve ser.

A ética corresponde ao posterior, pela colocação em prática das normas, dos códigos, das leis - é da moral vivida. Quando estamos no campo da moral vivida, estamos no campo da ética - são os máximos, é o da ação.

Refere-se também à ideia de novas circunstâncias - aspecto importante para esta análise. Poderão existir novas circunstâncias que permitem uma mudança do quadro moral e ético - sobretudo ético (ação). Não é uma mudança sumária a serviço de interesses pessoais, grupais ou ideológicos, como parece demonstrar o individualismo, o niilismo ou hedonismo deste tempo pós-moderno com o slogan relativista, relativismo moral (coisas da exterioridade), mas uma mudança que tem como bússola o maior valor, o ontológico (presente em todos os homens ditos normais). Santo Agostinho já nos havia dado essa pista com a ideia de chama interior que habita em nós, mas foi Kant ([s. d.]; 1998) que melhor a demonstrou ao referir que "duas coisas atormentam meu espírito - os céus grandiosos e infinitos sobre mim e a lei moral dentro de mim". É essa lei moral que habita em nós, que todos os dias nos julga e nos recomenda a boa ação (constante apelo ético) - o bem, o bom e o belo, trilogia que vai estruturar uma estética.

A Educação Física, tendo como distintivo máximo a ação/boa ação, tem em si um estilo privilegiado para desenvolver o apelo ético, o qual convoca sistematicamente:

- Estilo racional: julgar o que se faz, pensar sobre a ação.

- Ressonância afetiva: pela partilha de emoções, afetos, poesia, etc.

- Estilo relacional: pelo sentido comum e comunitário: comunidades altruístas, alteridade, pertença, valorização, atenção, cuidado. A ética relacional torna as pessoas melhores.

- Estilo ontológico: ser em si, o ser para si, ser experiência, intencionalidade, vivência (imanência, transcendência).

- Estilo ecológico: eu, comunidade, natureza.

- Estilo íntimo: a passagem da potência à ação, numa intimidade de cariz humanista, de felicidade total e, por isso, radical.

A Educação Física encontra na axiologia uma bússola orientadora para ser mais ético, mais nobre, ter caráter.

\section{Em jeito de uma síntese conclusiva}

Este ensaio é apenas uma pequena reflexão feita com liberdade de espírito, razão e coração. Tenta mostrar que a Educação Física tem uma essência primeira (ontológica/metafísica) que é do campo do universal, tem uma identidade universal a ponto de poder estar em todos os níveis do pensamento e da ação humana - do 
micro, passando pelo meso e terminando no macro (megaeventos). É do campo realista.

Mas a Educação Física tem também outra grande força - o seu idealismo, pela capacidade de convocar o sentido metafórico espiritualizado, por exemplo, a ideia de que, quando um homem se move, é toda a humanidade que se move.

O bom início, ir para a frente, ir para diante; o bom fim, sem fim. A Educação Física é isto: um bem maior - "coisa" ontológica, excelência educativa, e constituise como patrimônio e oportunidade humana. É palavra fundadora e fecunda, que tem e transporta futuro.

\section{Referências bibliográficas}

AZEVEDO, E.; SHIGUNOV, V. Reflexões sobre as abordagens pedagógicas em Educação Física. In: SHIGUNOV, V.; SHIGUNOV NETO, A. (Org.). A formação profissional e a prática pedagógica: ênfase nos professores de Educação Física. Londrina, 2001. p. 77-94.

BETTI, M. Valores e finalidades na Educação Física Escolar: uma concepção sistêmica. Revista Brasileira de Ciência do Esporte, v. 16, n. 1, p. 14-21, 1994.

BETTI, M. Educação Física e sociedade. São Paulo: Movimento, 1991.

BETTI, M. Educação Física e sociedade: a educação física na escola brasileira. 2. ed. São Paulo: Hucitec, 2009.

CUNHA, A. C. A Educação Física na Europa e em Portugal: realidades e possibilidades. [No prelo].

DAOLIO, J. Da cultura do corpo. São Paulo: Papirus, 1996.

FREIRE, J. B. Educação Física de corpo inteiro: teoria e prática da Educação Física. Campinas: Scipione, 1992.

GUEDES, D. P.; GUEDES J. E. R. P. Educação Física Escolar: uma proposta de promoção da saúde. Revista da APEF, Londrina, v. 7, n. 14, p. 16-23, 1993.

HILDEBRANDT, R.; LAGING, R. Concepções abertas no ensino da Educação Física. Rio de Janeiro: Ao Livro Técnico, 1986.

LE BOULCH, J. Psicocinética. Porto Alegre: Artmed, 1986.

KANT, E. Crítica da razão pura. Lisboa: Fundação Kalouste Gulbenkien, [s. d.].

KANT, E. Crítica da faculdade de juízo. Lisboa: Imprensa Nacional Casa da Moeda, 1998.

KUNZ, E. Transformação didático-pedagógica do esporte. Ijuí: Unijuí, 1996.

MORENTE, M. G. Fundamentos de filosofia: lições preliminares. São Paulo: Mestre Jou, 1980. 
NAHAS, M. Atividade física, aptidão física e saúde. Florianópolis: Material Didático, 1998.

OLIVEIRA, V. M. Educação Física humanista. Rio de Janeiro: Ao Livro Técnico, 1985.

PATRÍCIO, M. Ferreira. Filosofia do currículo e formação de professores: uma reflexão. In: MEDEIROS, E. (Coord.). Educação, cultura(s) e cidadania. Lisboa: Afrontamento, 2009

RICOEUR, P. De la morale à l'èthique et aux éthiques: un siècle de Philosophie. Paris: Centre Pompidou, 2000.

RICOEUR, P. Soi-même comme un autre. Paris: Seuil, 1990.

SOARES, C. L. et al. Metodologia do ensino da Educação Física. São Paulo: Cortez, 1992.

TANI, G. Educação Física Escolar no Brasil: seu desenvolvimento, problemas e propostas. In: SEMINÁRIO BRASILEIRO EM PEDAGOGIA DE ESPORTE. [Anais...]. Santa Maria: UFSM, 1998. p. 120-127.

António Camilo Cunha é professor doutor do Instituto de Educação da Universidade do Minho, Centro de Investigação em Estudos da Criança (Ciec), Portugal.

camilo@ie.uminho.pt

Recebido em 22 de outubro de 2012.

Aprovado em 18 de fevereiro de 2013. 